\title{
Institutional contexts in which micronutrient reference values are developed across Europe
}

\author{
L. Timotijevic ${ }^{1}$, M. M. Raats ${ }^{1}$, J. Barnett ${ }^{1}$, K. Brown ${ }^{1}$, L. Fernandez ${ }^{2}$, L. Dömölki ${ }^{3}$, J. Ruprich ${ }^{4}$, \\ R. A. Dhonukshe-Rutten ${ }^{5}$, A.-M. Sonne ${ }^{6}$, M. Hermoso ${ }^{7}$, B. Koletzko ${ }^{7}$ and L. Frost-Andersen ${ }^{8}$ \\ ${ }^{1}$ University of Surrey, Guildford GU2 7XH, UK, ${ }^{2}$ EUFIC, Brussels, Belgium, ${ }^{3}$ National Association for Consumer \\ Protection in Hungary, Budapest, Hungary, ${ }^{4}$ National Institute of Public Health, Brno, Czech Republic, \\ ${ }^{5}$ Wageningen University, Wageningen, The Netherlands, ${ }^{6}$ University of Aarhus, Aarhus, Denmark, ${ }^{7}$ Ludwig-Maximilians- \\ University of Munich, Munich, Germany and ${ }^{8}$ University of Oslo, Oslo, Norway
}

Progress has been made towards a coherent public health nutrition policy across Europe; however this remains a challenge mainly due to the variety of public health nutrition (PHN) policy traditions between countries and the diversity in scientific bases used to inform policy $^{(1)}$ This is particularly apparent in the misalignment of micronutrient reference values (MRV) across European countries and regions ${ }^{(2)}$. MRV often inform food and nutrition policies which are becoming an increasingly more important part of public health policies due to the burden associated with nutrition-related diseases.

Desk research and a questionnaire completed by key informants were used to collect data relating to the processes used to develop current MRV in thirty-one European countries, employing methods reported previously ${ }^{(2)}$. Data were collected on the process of scientific decision-making, including information on the transparency and openness of the process.

Considerable diversity was observed across Europe in the institutional context and nutrition policy imperatives driving the process of developing MRV. In those countries that have an established tradition of PHN policy the presence of advisory bodies is seen as key in developing MRV and advising government departments charged with applying science into policy and practice. This position is partly predicated by the institutional context (whether there is a dedicated department in charge of public health and how it is linked with other departments, the diversity of bodies and organisations involved in setting the agendas and making decisions in PHN, the broader governance context etc.), the PHN tradition and the historical context. Although the implication for nutrition policy is that there is a dedicated scientific institution or basis that acts as policy advisor and consequently facilitates development of dedicated national-level nutrition policies, it raises the issue of the extent to which scientific advisory committees are open, transparent and inclusive in the process. It appears that there is a considerable divide in terms of the openness and transparency of the process between the countries with an emerging democracy and those with established and increasingly participatory governance structures; also, in the complexity of the governance system in charge of developing MRV and hence the extent to which these levels are specifically tailored to national needs. In those countries with a more developed institutional architecture, scientific advisory bodies appear to be more than just a source of technical and scientific advice, instead acting as a link between evidence and policy. In particular, the remaining question is to what extent this model of informing national level of PHN policy can service the policy imperatives and the needs of wider society for the development of PHN policy that includes the framing of a wider section of society. In addition, the selection of the advisory panel members is not always clear and could lead to MRV that are eminence rather than evidence based.

This work was carried out within the framework of EURRECA, a Network of Excellence funded by the European Commission, project no FP6 036196-2.

1. World Health Organization Europe (2006) Comparative Analysis of Nutrition Policies in the WHO European Region. Copenhagen, Denmark: WHO Regional Office for Europe.

2. Doets EL, de Wit LS, Dhonukshe-Rutten RA et al. (2008) Eur J Nutr 47, Suppl. 1, 17-40. 